\title{
The laboratory diagnosis of tropical diseases with special reference to Britain: A review
}

\section{S. RIDLEY}

From the Hospital for Tropical Diseases, London
Diseases that are prevalent only or mainly in the tropics present a number of difficulties to the pathologist working in a temperate climate. They cut across the organizational divisions of pathology with the result that they may be encountered by workers in any department. All are involved, with the possible exception of the chemists. One has, too, to contend with the fact that because many parasitic infections are not usually of serious import they are apt to be treated lightly. Some, however, that are often asymptomatic may yet on occasion produce serious consequences. The recognized killers can mostly be treated, but being rare outside the tropics (malaria is becoming relatively common), many laboratory workers have insufficient experience of them. Another problem is that because many parasites need to be examined in the fresh state, while others, such as malaria, need to be treated as emergencies, it is not easy to arrange for parasitology to be dealt with by an area or reference centre, except for special cases, though this is possible with serological diagnosis. For all these reasons the general standard of diagnostic parasitology in Britain is uneven and often falls below that of other branches of parasitology. Yet the incidence of potentially pathogenic parasitism among immigrants from and visitors to the tropics is of the order of $30 \%$ (Allen and Ridley, 1971; Thompson, Hutchinson, and Johnston, 1972). Table I indicates the approximate frequency of different species and those that may cause death are listed in table II. The desirability of having a trained parasitology technician in every general laboratory to be responsible for the examination of all specimens, regardless of whether they happen to be blood, faeces, or urine, deserves very serious consideration. At the same time basic teaching in tropical diseases should be disseminated among workers in all divisions of pathology.

Tropical diseases call for relatively few special laboratory techniques. The aim of this article is to describe procedures of investigation and to draw attention to the major pitfalls in the way of a pathologist working in the temperate zones.

Received for publication 5 April 1974.

\begin{tabular}{|c|c|}
\hline Parasite & $\begin{array}{l}\text { No. of } \\
\text { Infections }\end{array}$ \\
\hline $\begin{array}{l}\text { Protozoa } \\
\text { E. histolytica, cysts (large race) } \\
\text { E. histolytica, invasive } \\
\text { Giardia } \\
\text { Malaria } \\
\text { Kala azar } \\
\text { Other }\end{array}$ & $\begin{array}{r}83 \\
9 \\
394 \\
94 \\
5 \\
3\end{array}$ \\
\hline $\begin{array}{l}\text { Nematodes } \\
\text { Ascaris } \\
\text { Enterobius } \\
\text { Hookworm } \\
\text { Strongyloides } \\
\text { Toxocara and larva migrans } \\
\text { Trichostrongylus } \\
\text { Trichuris } \\
\text { Filaria (blood spp) } \\
\quad \text { (Onchocerca) }\end{array}$ & $\begin{array}{r}102 \\
15 \\
129 \\
44 \\
12 \\
8 \\
276 \\
40 \\
28\end{array}$ \\
\hline $\begin{array}{l}\text { Trematodes } \\
\text { Schistosoma } \\
\text { Other }\end{array}$ & $\begin{array}{r}93 \\
7\end{array}$ \\
\hline $\begin{array}{l}\text { Cestodes } \\
\text { Hydatid cyst } \\
\text { Hymenolepsis } \\
\text { Taenia (cysticercosis 2) }\end{array}$ & $\begin{array}{r}2 \\
10 \\
36\end{array}$ \\
\hline $\begin{array}{l}\text { Arthropods } \\
\text { Lice } \\
\text { Myiasis }\end{array}$ & $\begin{array}{l}4 \\
5\end{array}$ \\
\hline Total & 1399 \\
\hline
\end{tabular}

Table I Number of infections with pathogenic parasites detected at the Hospital for Tropical Diseases in 1973

\begin{tabular}{lc}
\hline & $\begin{array}{c}\text { Mean No. } \\
\text { of Deaths }\end{array}$ \\
\hline Amoebiasis & $3 \cdot 3$ \\
Hydatid cyst & $7 \cdot 0$ \\
Leishmaniasis & 0.0 \\
Malaria & $6 \cdot 3$ \\
Schistosomiasis & 0.7 \\
Strongyloidiasis & 0.7 \\
Trypanosomiasis & 0.0 \\
& 18.0 \\
\hline
\end{tabular}

Table II Mean annual number of deaths reported in England and Wales 1969-1971

The reader is referred to textbooks for an account of the morphology of parasites, though a few brief comments will be made. 
As for the non-parasitic diseases, these do not fall into any clearly defined field, and I shall limit myself to a few conditions which are not unlikely to be encountered in Britain. Tropical infections due to viruses and fungi are not common, and as they are best dealt with by the reference centres for those conditions they are omitted from this review. Omitted also are toxoplasmosis, pneumocystis, tropical sprue, and the haemoglobinopathies, which will be covered by other reviews.

\section{Parasitology}

Diagnostic parasitology requires two special skills. The first is the detection of a parasitic organism, often small, scanty, or inconspicuous against a heterogeneous background. Here there is no substitute for experience, and it is not commonly recognized how much experience is required even though the laboratory worker may have done a special course in parasitology. Of all the 'parasites' referred to this laboratory for identification approximately half prove not to be parasites. There should therefore be no shame in sending any dubious object to a reference centre.

The second special skill is the identification of a parasite once spotted. Here textbooks are of considerable value, even though they are no substitute for experience. The organism presented to the laboratory, on which attention should be concentrated, is usually in the phase of its life cycle by which the parasite is transmitted from the human host to the next host or vector. This is commonly a cyst, ovum, or larva. Protozoa may be encountered in other phases of their cycle, but among helminths, ascaris, enterobius, and the tapeworms are the only adult worms that are likely to be sent for examination. For convenience, therefore, in this article the classification of parasites is not systematic but is roughly based on the type of specimen in which the parasite is most likely to be found.

In considering identification mistakes will sometimes be avoided if one knows what parts of the world the patient has visited. In considering diagnosis it should be remembered that where there is one parasitic infection there may be others.

The account that follows is written on the assumption that a microscope with high class optics is available, and it is strongly recommended that the instrument should be for the sole use of the parasitologist. Fluorite objectives or the equivalent, eg, 'microplan', are a big advantage for all powers. The optics of the condenser are less important; the 'flip-top' variety is very convenient. A good high intensity illumination system is required and so is a calibrated micrometer eyepiece.

\section{Examination for Intestinal Parasites}

EXAMINATION OF FAECES

\section{Direct examination}

A small quantity of faeces is emulsified in a drop of saline on a slide and the whole cover slip is examined under a $\times 10$ objective, preferably with $a \times 10 \stackrel{\mathbb{\Phi}}{2}$ eyepiece. There must be sufficient material to in examine but if there is too much and parts of the preparation are completely opaque it will be impossible to detect small protozoa. To achieve the necessary degree of refraction the light must be centred, the condenser lowered a little or the top lens swung out and the substage diaphragm partly i closed but dim illumination is to be avoided. Cysts should stand out brightly. Any suspicious object + should be looked at under the $\times 40$ objective, and $\omega_{7}$ each time this is done the illumination will have to be 의 adjusted. Finally, to observe the detailed structure of protozoa it may be necessary to use the oil immersion objective, though this should be left until the whole preparation has been screened as the oil cannot be removed from the unfixed coverslip.

Positive staining is not recommended for the first examination. By making everything brown Lugol's iodine (diluted to half strength with $10 \%$ acetic acid) makes it more difficult to detect parasites, and although it stains nuclei it obscures chromidial bars. It is helpful in identifying a glycogen mass, and is a convenient way of killing fast moving flagellates. It may therefore be useful for a second preparation but with experience less and less reliance will be placed on it.

Negative staining may be helpful as the coloured background makes it easier to spot cysts. The best of these stains is that of Thompson (1972) which also enhances somewhat the structure of cysts: add a drop of a mixture in equal parts of $10 \% \mathrm{w} / \mathrm{v}$ aqueous nigrosin and $1 \% \mathrm{w} / \mathrm{v}$ aqueous alcian blue.

\section{Concentration methods}

These may be of the flotation or sedimentation types. The former give a very clean preparation of $\mathrm{N}$ cysts and ova but the zinc sulphate method of $N$ Faust, d'Antoni, Odom, Miller, Peres, Sawitz, N Thomen, Tobie, and Walker (1938), which is commonly employed, has the disadvantage that the heavier ova, including Schistosoma and Fasciola, are lost. Of the many sedimentation methods none has been found as effective as Ritchie's formol-ether technique. The modification of Allen and Ridley (1970) is recommended (the sieve used in this method has pores of 400 to $450 \mu \mathrm{m}$, which should be stated when ordering). All cysts, ova, and larvae are effectively concentrated. The use of formalin some- 
what enhances the visibility of the structures of cysts. Stains can be used with the concentrate, including malachite green (Sargeaunt, 1962).

\section{Procedure of investigation}

It is worthwhile to concentrate all faecal specimens. In addition, unformed stools, or those with blood or mucus, must be given a direct examination for trophozoites (amoebae, flagellates, and ciliates). Such trophozoites, including those of Entamoeba histolytica, mostly survive for a few hours in faeces at room temperature and do not call for excessive haste in examination, though they gradually become less active. Those of Balantidium coli, which cause dysentery in pig handlers, and of Dientamoeba fragilis, which can probably cause mucous diarrhoea, are likely to be lost if the stool is not examined within $\mathbf{3 0}$ minutes.

For 'clean' formed stools it is sufficient to examine only the concentrate as trophozoites will not be present. Such stools (or better the concentrate) may be stored overnight in the refrigerator $\left(4^{\circ} \mathrm{C}\right)$ if necessary.

It is not possible to say categorically how many stools should be examined. It can be calculated that with the recommended concentration technique and a skilled examiner the first examination will detect $73 \%$ of all parasitic infections, the second and third 88 and $96 \%$. But these figures do not apply to infections with $E$. histolytica and Strongyloides stercoralis, the excretion of which in faeces is erratic. The routine in this laboratory is to examine two specimens of stool, with additional examinations if symptoms warrant it.

\section{Preservation of specimens}

For the bulk preservation of specimens containing parasites other than trophozoites, emulsify the specimen in $10 \%$ formol-saline. But note that fixed specimens cannot be effectively concentrated. For the preservation of trophozoites polyvinyl alcohol fixation (Brooke and Goldman, 1949) is widely used, though Scholten (1972) recommends Schaudinn's fluid in preference to PVA. Permanent preparations of protozoa are best fixed in Schaudinn and stained with iron haematoxylin or one of its modifications.

\section{IDENTIFICATION OF PARASITES IN FAECES}

\section{Amoebae}

Amoebae have to be distinguished from macrophages, which also may ingest red cells. The pseudopodial activity of macrophages in stool is shortlived so that confusion is most likely to arise in very fresh preparations. The nucleus of an amoeba is usually visible whereas the macrophage nucleus is not seen in unstained preparations.

\section{Precysts}

Precysts are the most difficult stage of a protozoon on which to make species identification. The amoeba has extruded red cells or other ingested matter, has ceased to be active, and is rounded up into a cyst. But there is only one nucleus and usually no chromidial bars. In the rare event of a specimen showing nothing but precysts it is advisable to ask for a second specimen before making a diagnosis. However, a precyst with an Entamoeba nucleus in the presence of a red cell exudate is probably $E$. histolytica.

\section{Cysts}

Cysts are the common form of presentation of protozoa in temperate climates. They are brightly refractile and have a perfectly smooth surface contour. Nuclei are always present though they may be difficult to see in the smallest cysts such as Endolimax nana. The number of nuclei depends not only on species but on the maturity of the cyst.

\section{Ova}

Ova are fairly easy to identify from textbook illustrations. The eggs of trematodes (flukes) all have an operculum (cap) at one end, except for the schistosoma ova which have spines. Those of the cestodes (tapeworms) are characterized by an onchosphere (embryo) with hooklets situated within a thick-walled shell except for Diphyllobothrium which has operculated ova. The eggs of the nematodes (roundworms) have no special distinguishing features.

Infections with intestinal parasites can nearly all be diagnosed by means of stool examinations as described. Only a few need special comment.

\section{AMOEBIASIS}

\section{E. histolytica: identification and pathogenicity}

Trophozoites, which are invasive and ingest red cells, are larger than those of commensals which live in the lumen of the gut ('minuta' phase). The cysts of the two phases, however, are indistinguishable. Small race cysts of $E$. histolytica (less than 10 $\mu \mathrm{m})$ are regarded by some as a separate species or subspecies of $E$. harmanni, though there is some individual overlap in size. The small race is probably non-pathogenic.

Of the various characteristics of E. histolytica cysts the only one which by itself is reliable for specific diagnosis is the finding of chromidial bars with round ends. Chromatoids, however, are often absent and reliance must then be placed on a combination of other features.

Immunofluorescent identification of amoebae appears to be a successful method for the species 
identification of trophozoites, but not of cysts, in faeces or culture (Parelkar and Stamm, 1973) and also in tissues (Parelkar, Stamm, and Hill, 1971). Specific antisera are required.

Claims have been made that $E$. histolytica can be detected by faecal culture in a number of cases that are missed by other methods (Eschar, Schiff, Yaron, and Alkan, 1968; Robinson, 1968). Most workers, however, do not regard culture as a very useful or practicable routine procedure. The trophozoites of $E$. histolytica and E. coli are not easy to distinguish in culture by ordinary microscopy.

\section{Amoebic dysentery}

Although the trophozoites are commonly detected at the first stool examination this is not always the case. Patients with repeatedly negative stools, and diagnosed as ulcerative colitis, may occasionally reveal $E$. histolytica through examination of sigmoidoscopic scrapings of the ulcers, or as a result of giving corticosteroids (Mody, 1959; Kanani and Knight, 1969). The indirect fluorescent antibody test (IFA) cannot be relied on in amoebic dysentery, though it is often positive (Jeanes, 1969; Ambroise-Thomas and Thai, 1972).

An amoeboma is a nodular inflammatory mass beneath an intact mucosa, which must not be mistaken for a tumour. E. histolytica is often not detected in the faeces, but the IFA is usually positive.

\section{Hepatic abscess}

A clinical diagnosis can be adequately confirmed by a positive immunofluorescent antibody test. The positivity rate of this test is almost $100 \%$, and at high titre the specificity is good.

If a large abscess has to be drained, discard the bulk of the 'anchovy sauce' pus, and keep separate the last $5 \mathrm{ml}$ which drains from the wall of the abscess. This should be examined without delay for E. histolytica trophozoites.

\section{GIARDIASIS}

Giardia lamblia at present appears to be the commonest parasite in Britain, and the same may well be true of other temperate countries. It is also the most contagious of the protozoa. It is a recognized cause of malabsorption, especially in children, though equally it may be asymptomatic.

It is nearly always seen in cyst form, even in symptomatic cases, and is easily recognized.

\section{ENTEROBIUS}

For diagnosis, moisten a swab with saline, wipe firmly round the anal skin, and plunge it into about $5 \mathrm{ml}$ of saline. Centrifuge and examine the deposit.
This gives a better recovery rate than the Sellotape $\frac{\overrightarrow{0}}{\vec{\sigma}}$ method.

STRONGYLOIDIASIS

The difficulty of diagnosing light infections has $\frac{}{0}$ already been referred to. Much more important is $\overline{\bar{c}}$. the hyperinfection which is apt to develop, perhaps $\underset{\alpha}{\vec{\alpha}}$ after many years' residence in a temperate country. Such infections may present with septicaemia, and ${ }^{\infty}$ they are often fatal. The flare-up may come about as $\vec{O}$ a result of corticosteroid therapy or it may be $\overrightarrow{\vec{H}}$ 'opportunistic' (Rivera, Maldonado, Velez-Garcia, $\stackrel{\omega}{\omega}$ Grillo, and Malaret, 1970; Adam, Morgan, Persaud, 궁 and Gibbs, 1973). Filariform larvae are usually numerous in the stools; this infective stage is not -7 normally seen.

Serology can be used as a screening test for strongy- फ्ञ loidiasis (Coudert, Ambroise-Thomas, Thai, and $\mathrm{O}$ Pothier, 1968; Kanani and Rees, 1970).

\section{FASCIOLIASIS}

Outbreaks of Fasciola hepatica infection are liable to $\vec{C}$ occur in the United Kingdom (Facey and Marsden, 1960; Hardman, Jones, and Davies, 1970). Early diagnosis is clinical (pyrexia, tender liver, and eosinophilia) as the eggs do not appear in the stools during the first three months, and are always scanty. Serodiagnosis is helpful, especially in the early stage (Everall, 1970).

\section{Histology}

If the adult worms are ever encountered in histological sections they can be distinguished by their branched and coiled gut; all other flukes have a ? straight twin gut. The developing larvae in migrating $\frac{3}{3}$ across the liver may cause necrotic tracks with palisading of histiocytes and heavy infiltration of eosinophils (see Thorpe and Ford, 1969).

\section{Examination of Urine}

Trichomonas vaginalis may cause urinary tract $N$ infections in patients of either sex. Microfilariae of $N$ Wuchereria bancrofti and Onchocerca volvulus may occasionally be observed in urine, and threadworm ova may be present as contaminants.

\section{SCHISTOSOMIASIS}

Ova of Schistosoma haematobium may be found in the sediment of any specimen of urine. Possibly the best method is to collect and pool the terminal portions of each specimen that is passed over a period of 24 hours. The sediment is centrifuged and examined. 
In old infections ova may occasionally be found in a biopsy of the bladder mucosa when urine examination is negative. S. haematobium ova, unlike those of $S$. mansoni, are not acid-fast (Muller and Taylor, 1972). A useful study of the histological reaction to Schistosoma ova has been made by von Lichtenberg, Erickson, and Sadun (1973). The complement fixation test (CFT) is a useful screening test for urinary or intestinal infections (Kagan and Pellegrino, 1961).

\section{Examination of Sputum}

This is not a very rewarding procedure. Sputum is the commonest route for the discharge of the eggs of Paragonimus westermani, which are, however, also excreted in faeces. A variety of parasites may be coughed up on occasion.

\section{Examination for Blood Parasites}

\section{MALARIA}

Ordinary haematological methods are not altogether satisfactory for staining malaria parasites. The results are too pale and Schüffner's dots are seldom demonstrated. Another consideration is that in conventional thin films parasites are often inconveniently sparse. Parasitaemia may be light either because the patient is partially immune or because in two of the four human species, Plasmodium malariae and $\boldsymbol{P}$. ovale, it usually is light even in severe infections. Thick films, in spite of their relative inefficiency (Dowling and Shute, 1966), do show many more parasites. They should be examined for 10 minutes. In addition specially stained thin films are needed for their superior morphological clarity.

\section{Thin films}

The first essential for good staining is that all diluents must be of $\mathrm{pH} 7 \cdot 2$, whichever stain is employed. Though the best results are probably obtained with Field's stabilized Leishman, Giemsa is satisfactory, more convenient for occasional use, and is superior to ordinary Leishman.

1 Fix with methyl alcohol ( $\left.\frac{1}{2} \mathrm{~min}\right)$ and stain with Giemsa diluted 1 in 10 immediately before use. The staining time depends on the brand; with Gurr's Giemsa R66 30 minutes is sufficient. Flush off the stain with buffered water. To avoid a deposit, staining should be carried out in a trough, and the stain discarded after use. For small numbers of slides a convenient trough can be made by mounting two slides on a plastic sheet. The slide to be stained is placed upside down across the other two slides, and the stain is run in underneath it.

\section{Thick films}

The principle is that the red cells are lysed before staining. The film, therefore, cannot be fixed but must be dried thoroughly and handled with care.

Prepare a thick film by spreading out a drop of blood until the film is sufficiently translucent to allow the hands of a watch to be seen; it should normally show 10-15 leucocytes per micro-field. Films that are too thick flake off. Dry at $37^{\circ} \mathrm{C}$ for at least 15 minutes. Stain with Giemsa as for thin films, but for a somewhat shorter staining time and omitting the initial fixation. Dry thoroughly. Shute (1966) states that a clearer background is achieved by diluting the stain with normal saline (pH 7.2) instead of water.

A satisfactory and very quick alternative method is Field's stain. It is important to select for examination a good part of the preparation, where the stain shows both blue and red elements.

The morphological criteria for identifying malaria parasites in thick films are the same as for thin films. But the appearances are a little different, the parasites being more compact and opaque. Schüffner dots, which have the same diagnostic significance as enlargement of the red cell, can often be detected around the parasites.

\section{Species identification}

As regards morphology, there is space only to remark that whereas $P$. vivax and $P$. ovale parasites form a pair with many points in common, the four human species can be placed in a quadrant on the basis of the number of merozoites in a fully developed schizont on the one hand, and on the other enlargement of the red cell (or presence of Schüffner's dots).

\begin{tabular}{lll}
\hline & \multicolumn{2}{l}{$\begin{array}{l}\text { Enlargement of Red Cells } \\
\text { (Schüffner Dots) }\end{array}$} \\
\cline { 2 - 3 } & + & - \\
\hline $\begin{array}{c}\text { Schizonts } \\
\leqslant 12 \text { nuclei }\end{array}$ & Vivax & Falciparum \\
\hline
\end{tabular}

The vivax-ovale pair causes enlargement whereas $P$. falciparum and $P$. malariae do not. The first and third of the four have more than 12 merozoites in the schizont, the second and fourth less than 12 . Immature schizonts, however, have fewer merozoites. The most important of these is the pre-schizont of $P$. falciparum, which is of grave prognostic import, falciparum shizonts not normally being seen in peripheral blood. This form is a ring with two or more masses of chromatin. It may be recognized as falciparum because there are only one or two clumps of pigment, whereas all other species show 20 or more small grains of pigment (Shute and Maryon, 
1969). Another danger signal in falciparum malaria is the finding in thick films of fused masses of endothelial cell nuclei (Goodall, 1973).

\section{Serology of malaria}

A positive serological result (usually IFT) may indicate only a previous infection. The test is useful mainly for epidemiological purposes, but for diagnosis it is of some value in patients who may be expected to have a high immunity, and in those who have already received some chemotherapy before a blood specimen is sent for examination (Voller, 1971; Symposium, 1972). It may also be helpful in elucidating the aetiology of splenomegaly and the nephrotic syndrome.

\section{Malaria pigment \\ Malaria pigment in histological section consists of small, dark brown, birefringent granules of haemo- zoin. It is chemically indistinguishable from formalin pigment, which, however, is more irregular in size and shape and more spiky. In liver malaria pigment is intracellular in Kupffer cells, but in spleen it may be partly extracellular and hence more difficult to distinguish from formalin pigment.}

\section{AFRICAN TRYPANOSOMIASIS}

The motile flagellates can be seen by direct microscopy of a wet film of blood or they may be stained by Giemsa in a thick dried film. In the early stage it is important to look for them in the aspirate of enlarged lymph nodes, usually in the posterior triangle of the neck, and in the cerebral stage they must be looked for in the cerebrospinal fluid. Recognition is simple.

The two trypanosomes that cause human sleeping sickness, Trypanosoma gambiense and $T$. rhodesiense, are morphologically identical and closely related members of the $T$. brucei group. The new nomenclature is $T .[b]$ gambiense etc.

Although agglutination tests are giving promising results in African trypanosomiasis there is as yet no serological test of proved reliability. It is better to rely on finding the organisms, which is not usually difficult.

Sleeping sickness has an insidious onset, presenting possibly with behaviour changes, and the consequences of overlooking it are disastrous.

\section{FILARIASIS}

Filtration is by far the best method of searching for the microfilariae of blood. Ten $\mathrm{ml}$ of heparinized blood is lysed with saponin (this stage is not essential) and passed through a $5 \mu \mathrm{m}$ nucleopore filter (which is much better than a millipore). Saline is flushed through to wash out debris, and the filter disc is examined under the microscope. The microfilariae can be stained with Giemsa (30 min) or Harris's haematoxylin. They will not be found in thick films except in heavy infections which in Britain are rare.

The important microfilariae of blood are Wuchereria bancrofti, Brugia malayi, and Loa loa, all with sheath, and Acanthocheilonema perstans which is unsheathed.

\section{Onchocerciasis}

Onchocerca volvulus is a parasite of skin rather than blood but it is convenient to discuss it here. The unsheathed microfilariae are found in skin snips, the best chance being in the neighbourhood of a nodule but otherwise snips are taken at random, eg, from the buttocks. A fold of skin is pressed between finger and thumb and a shaving, taken with a razor, is placed in a drop of saline without teasing and covered. After 15 to 30 minutes the microfilariae may be seen swimming out of the snip into the saline.

A biopsy of an onchocerca nodule, if present, will demonstrate the adult worms.

\section{Serology}

Serological tests are needed to supplement the direct search for microfilariae, especially in hyperreactive patients when the microfilariae are scanty or undetectable, though symptoms are fairly acute and the eosinophilia is high. Complement-fixation tests and indirect haemagglutination (IHA) with adult worm antigen are positive in a fairly high proportion of such patients, but they have a rather low specificity and cross react with some other nematodes if tissue invasion occurs (see Kagan, 1963 for a review). The immunofluorescence test is more specific, especially with microfilariae as antigen.

\section{Examination for Tissue Parasites}

Some parasites are not readily detectable in blood or $\rightarrow$ excreta. A few may be diagnosed from aspirates, but most tissue parasites are not seen except, on occasion, N in histological sections. Immunodiagnosis is of greater importance.

KALA A Z A R

The Leishmania amastigotes (Leishman-Donovan bodies) are normally sought for in bone marrow smears, stained as for thin blood films (see malaria). In this situation they are scanty and often extracellular. In spleen they are more numerous, but splenic puncture is not free of risk. It is advisable, therefore, to combine a marrow smear with inoculation for culture. The organisms may also be detected by liver biopsy in Kupffer cells. They are distin- 
guished from Histoplasma by the presence of a kinetoplast beside the nucleus and in being PAS negative.

\section{Culture}

The promastigotes (flagellate form) are found in the water of condensation at the bottom of an NNN culture medium after two to three weeks' incubation at $22-25^{\circ} \mathrm{C}$. It follows that it is essential for the NNN medium to be fairly fresh and certainly not dried up.

\section{Serology}

In view of the slight uncertainty about finding organisms in marrow, and the delay in culture, there is a place for serology. The IFT gives good results, and also provides some sort of test of cure. No reliance can be placed on the formol gel test.

\section{CUTANEOUS LEISHMANIASIS}

The amastigote of $L$. tropica, morphologically identical to that of $L$. donovani, is sought for in a Giemsa-stained smear of material obtained by puncture from the edge of the sore or ulcer. Cases that are negative by microscopy may yet sometimes give a positive culture on NNN medium. Serology is of little value.

\section{Histology}

There is an immunological spectrum in cutaneous leishmaniasis, which is reflected in the histology in much the same way as in leprosy (Turk and Bryceson, 1971). In the low immune form there are numerous organisms that can be seen readily in a well stained haematoxylin-eosin section. In the intermediate stage the histology is characterized by clear areas composed of histiocytes in an otherwise mixed infiltrate; the histiocytes may show pallisading and later develop as epithelioid cells. Culture should be positive. In the high immune type there is a pronounced tuberculoid granuloma, without caseation, in which no organisms are to be seen unless perhaps faintly stained dead ones. In these cases the skin test is positive.

\section{Leishmania}

A positive leishmanin skin test indicates immunity to leishmaniasis of any form. It is usually negative when organisms are numerous but positive when there is a tuberculoid histology, especially in infections with $L$. tropica, and is then useful for confirmation of diagnosis. It may also become positive after treatment.

\section{CHAGAS' DISEASE}

This South American form of trypanosomiasis (quite distinct from the African variety) is rare in Britain, and if any patients are encountered they are likely to be in the chronic phase. As a screening procedure serology gives good results (Cerisola, 1970; Carmargo, Hoshino, and Sequeira, 1973). For confirmation of the diagnosis it has recently been claimed that three blood cultures on Warren's medium will detect $100 \%$ of cases (Albuquerque, Fernandes, Funayama, Ferriolli, and di Siqueira, 1972). This procedure seems likely to supplant xenodiagnosis.

\section{TRICHINIASIS}

Trichiniasis is not a tropical condition. Outbreaks have occurred in Britain (Evans and Lennox, 1953; Semple, Davies, Kershaw, and St Hiu, 1954). Sporadic cases and latent infections occur also (Harvey and Kershaw, 1964). Diagnosis is made by muscle biopsy, using serial sections or trypsin digestion to aid the search for the encysted parasite. Serology is a useful screening procedure (Kagan, 1960).

\section{HYDATID CYST}

Diagnosis is partly clinical and radiological, partly by immunodiagnosis. Results of serology generally speaking are good with active infections but poor with dead cysts (Kagan, 1968; Coudert et al, 1969).

The diagnosis of dead cysts depends as a rule on the histology of the excised specimen and is unsatisfactory. Whereas a live cyst may be recognized by the presence of scolices in the fluid, and the characteristic laminated membrane which is the parasite, a dead cyst is featureless. In the uncommon infiltrating type of alveolar hydatid due to Echinococcus multilocularis (Gemmell, 1959) the multiple cysts show a laminated membrane but scolices are rare (Walshe, 1954).

\section{CYSTICER COSIS}

A Cysticercus cellulosae is the larval stage of Talnia solium, and consists of a scolex (head) invaginated into a bladder-like cyst. It may be recognized in histological sections by its invagination canal, and serial sections will demonstrate the hooklets and one or more of the four suckers. Serology is useful as a screening test.

HYPERACTIVE TISSUE RESPONSE

A hyperactive response with heavy eosinophilia is not uncommonly produced by zoonotic species of parasite which are ill-adapted to man, or less often by human species to which an individual host displays unusual hypersensitivity. This is an oversimplified view of the host-parasite relationship, as Beaver (1969) points out, but it remains true that there are a number of conditions in which either the parasite does not survive in the human host though 
it produces a serious lesion or the adult worm survives but the life cycle does not go to completion and it is impossible to find ova or larvae. In such cases diagnosis is mainly serological.

Examples of this situation are tropical pulmonary eosinophilia usually due to some form of filaria; the closely related Loeffler's syndrome which may be due to Strongyloides; visceral larva migrans of which the prototype is Toxocara canis (Woodruff, 1970); cutaneous larva migrans due to canine or other Ankylostoma; eosinophilic phlegmon of the gut due to Anisakis (Ashby, Appleton, and Dawson, 1964; Williams, 1965); and dermatitis due to zoonotic forms of schistosomiasis, which has been reported in Britain (Knight and Worms, 1972).

\section{HISTOLOGY OF HELMINTHIC LESIONS}

Whereas protozoal species sometimes produce a fairly characteristic histological picture, helminths do not. Diagnosis depends on finding the adult worm, larva, or ovum. The problem is that the reaction which draws attention to the site of the parasite is often the cause of its destruction beyond recognition.

There are a few features which in a general way suggest a helminthic aetiology, and warrant the cutting of serial sections if the parasite or its remains is not seen in the first section. It may never be found. (1) Intense, widespread eosinophilia, with or without Charcot-Leyden crystals (which signify eosinophilia either present or recent). (2) Focalized eosinophilic necrosis at the site of destruction. (3) A granuloma, which by contrast with eosinophilia, is circumscribed, usually solitary and spherical. Schistosoma ova, however, may produce multiple tuberculoid granulomata. (4) A necrotic track due to a migrating larva. (5) Pallisading of histiocytes around one of the above lesions, or around a cavity made by an adult worm. (6) A foreign-body giant cell reaction. The giant cells may assume the form and contour of the parasite they have ingested. (7) Fibrosis and calcification These often have no special features.

\section{Immunodiagnosis}

Serological tests are generally better for clinical diagnosis than skin tests, which are of value mainly for epidemiological surveys. Helminthic skin tests, unlike those for protozoa, fungi, or bacteria, are of the immediate hypersensitivity (IgE) type and they are read at 20 minutes.

Almost all types of serological test have been applied to parasitology. Of those in common use the usual order of sensitivity is haemagglutination immunofluorescence, and complement-fixation tests. After treatment the fall in titre with haemagglutination is delayed almost indefinitely so that it may be difficult to distinguish active from past infection. The fall is most rapid with CFT. But the advantage of a particular test cannot be discussed without regard to the antigen employed. The use of serodiagnosis is summarized briefly in table III.

\section{Non-parasitic Disease}

Only a few cursory remarks are possible.

Imported virus diseases are surprisingly few, and the more serious forms are prevented by vaccination and other control measures such as the quarantine of animals. Lassa fever, however, is an alarming possibility (Monath, Mertens, Patton, Moser, Baum, Pinneo, Gary, and Kissling, 1973; Woodruff, Monath, Mahmoud, Pain, and Morris, 1973).

\section{LEPROSY}

Leprosy was reviewed by Rees and Ridley (1973). The diagnosis is partly clinical and partly histological. The main problem with the latter is the identification of the early lesion (Nayar, Nayaranan, and Job, 1972; Ridley, 1973); and the differential

\begin{tabular}{ll}
\hline Infection & Purpose of Test \\
\hline Amoebiasis & $\begin{array}{l}\text { Test of Cure by } \\
\text { Fall of Titre in }\end{array}$ \\
& $\begin{array}{l}\text { Diagnosis of amoebic abscess or amoeboma } \\
\text { Strong positive is specific }\end{array}$ \\
Chagas's disease & Diagnosis of chronic cases, fairly specific \\
Cysticercosis & Diagnosis, fairly specific \\
Fascioliasis & Screening test, most valuable in early cases \\
Filariasis & Screening for filariasis, strongyloidiasis, and 'tropical eosinophilia' \\
Hydatid & Diagnosis, fairly specific \\
Malaria & Diagnosis of immune or partially treated cases, specific \\
Schistosomiasis & Screening, crossreacts with trichiniasis \\
Toxocariasis & Diagnosis, moderately specific \\
Trichiniasis & Screening \\
\hline
\end{tabular}

Table III Serological tests available in Britain with an indication of their purpose ${ }^{1}$

${ }^{1}$ Further information should be sought from the laboratory in which the test is performed. 
diagnosis of the tuberculoid lesion (Wiersema and Binford, 1972). In both cases diagnosis depends on finding nerve involvement, if possible in association with acid-fast bacilli. For comparison with table I, the number of cases diagnosed at this hospital in 1973 was 15.

\section{RELAPSING FEVER}

This is more likely to be thought of than to be found. The organisms are readily demonstrated in the blood by routine stains but if in doubt concentration can be performed by microhaematocrit (Goldsmid and Mahomed, 1972).

I am very much indebted to $\mathrm{Mr} \mathrm{A}$. $\mathrm{H}$. Moody and Miss P. L. Johnson for their assistance in evaluating the methods described. Information given in table II was kindly supplied by Mrs C. M. Mardon of the Office of Population Censuses and Surveys.

\section{References}

Adam, M., Morgan, O., Persaud, C., and Gibbs, W. N. (1973). Hyperinfection syndrome with Strongyloides stercoralis in malignant lymphoma. Brit. med. J., 1, 264-266.

Albuquerque, R. D. R., Fernandes, L. A. R., Funayama, G. K., Ferriolli, F., and de Siqueira, A. F. (1972). Hemoculturas seriadas com o meio de Warren em pacientas com reação de Guerreiro Machado positiva. Rev. Inst. Med. trop. Sao Paulo, 14, 1-5.

Allen, A. V. H., and Ridley, D. S. (1970). Further observations on the formol ether concentration technique for faecal parasites. $J$. clin. Path., 23, 545-546.

Allen, A. V. H., and Ridley, D. S. (1971). A survey of parasitic infections in Britain. J. Trop. Med. Hyg., 74, 83-86.

Ambroise-Thomas, P., and Thai Kien Truong (1972). Fluorescent antibody test in amebiasis. Amer. J. trop. Med. Hyg., 21, 907912.

Ashby, B. S., Appleton, P. J., and Dawson, I. (1964). Eosinophilic granuloma of gastro-intestinal tract caused by herring parasite Eustoma rotundatum. Brit. med. J., 1, 1141-1145.

Beaver, P. C. (1969). The nature of visceral larva migrans. J. Parasit., 55, 3-12.

Brooke, M. M., and Goldman, M. (1949). Polyvinyl alcohol-fixative as a preservative and adhesive for protozoa in dysenteric stools and other liquid materials. J. Lab. clin. Med., 34, 15541560.

Camargo, M. E., Hoshino, S., and Siqueira, G. R. V. (1973). Hemaglutination with preserved, sensitized cells, a practical test for routine serologic diagnosis of American trypanosomiasis. Rev. Inst. Med. trop. Sao Paulo, 15, 81-85.

Cerisola, J. A., Alvarez, M., and de Rissio, A. M. (1970). Imunodiagnóstico da doença de Chagas. Evolução sorológica de pacientes com doença de Chagas. Rev. Inst. Med. trop. Sao Paulo, 12, 403-411.

Coudert, J., Ambroise-Thomas, P., Kien Truong Thai, and Pothier, M. A. (1968). Diagnostic sérologique de l'anguillose humaine par immuno-fluorescence. Bull. Soc. Path. Exot., 61, 74-80.

Coudert, J., Despeignes, J., and Battesti, R . (1969). Valeur diagnostique actuelle de la reaction de fixation du complément dans le kyste hydatique. Ann. Parasit. hum. comp., 44, 375-385.

Dowling, M. A. C., and Shute, G. T. (1966). A comparative study of thick and thin blood films in the diagnosis of scanty malaria parasitaemia. Bull. Wld Hlth Org., 34, 249-267.

Eshchar, J., Schiff, I., Yaron, V., and Alkan, W. J. (1968). Infection with Entameba histolytica and the clinical syndrome of amebiasis. Israel J. Med. Sci., 4, 1254-1259.

Evans, A. D., and Lennox, M. (1953). An outbreak of trichiniasis in Barry, Glamorgan. Brit. med. J., 2, 131-133.

Everall, P. H. (1970). The double diffusion precipitin test in human fascioliasis. J. clin. Path., 23, 636-639.

Facey, R. V., and Marsden, P. D. (1960). Fascioliasis in man: an outbreak in Hampshire. Brit. med. J., 2, 619-625.

Faust, E. C., D'Antoni, J. S., Odom, V., Miller, M. J., Peres, C., Sawitz, W., Thomen, L. F., Tobie, J., and Walker, J. H. (1938). A critical study of clinical laboratory technics for the diagnosis of protozoan cysts and helminth eggs in feces. Amer. J. trop. Med., 18, 169-183.

Gemmell, M. A. (1959). The fox as a definitive host of Echinococcus and its role in the spread of hydatid disease. Bull. Wld Hlth Org., 20, 87-99.

Goldsmid, J. M., and Mahomed, K. (1972). The use of the microhematocrit technic for the recovery of Borrelia duttonii from the blood. Amer. J. clin. Path., 58, 165-169.

Goodall, H. B. (1973). Giant nuclear masses in the lungs and blood in malignant malaria. Lancet, 2, 1124-1126.

Hardman, E. W., Jones, R. L. H., and Davies, A. H. (1970). Fascioliasis-a large outbreak. Brit. med. J., 3, 502-505.

Harvey, P. W, and Kershaw, W. E. (1964). Low incidence of latent trichinosis near Blackpool compared with incidence elsewhere in England and Wales. Brit. med. J., 2, 1632-1634.

Jeanes, A. L. (1969). Evaluation in clinical practice of the fluorescent amoebic antibody test. J. clin. Path., 22, 427-429.

Kagan, I. G. (1960). Trichinosis: a review of biologic, serologic and immunologic aspects. J. infect Dis., 107, 65-93.

Kagan, I. G. (1963). A review of immunologic methods for the diagnosis of filariasis. J. Parasit., 49, 773-798.

Kagan, I. G. (1968). A review of serological tests for the diagnosis of hydatid disease. Bull. Wld Hlth Org., 39, 25-37.

Kagan, I. G., and Pellegrino, J. (1961). A critical review of immunological methods for the diagnosis of bilharziasis. Bull. Wld Hith Org., 25, 611-674.

Kanani, S. R., and Knight, R. (1969). Relapsing amoebic colitis of 12 years standing exacerbated by corticosteroids. Brit. med. J., 2, 613-614.

Kanani, S. R., and Rees, P. H. (1970). The diagnosis of strongyloidiasis with special reference to the value of the filarial complement fixation test as a screening test. Trans. roy. Soc. trop. Med. Hyg., 64, 246-251.

Knight, R., and Worms, M. J. (1972). An outbreak of cercarial dermatitis in Britain. Trans. Roy. Soc. trop. Med. Hyg., 66, 21,

Mody, V. R. (1959). Corticosteroids in latent amoebiasis. Brit. med.J. $2,1399$.

Monath, T. P., Mertens, P. E., Patton, R., Moser, C. R., Baum, J. J. Pinneo, L., Gary, G. W., and Kissling, R. E. (1973). A hospital epidemic of Lassa fever in Zorzor, Liberia. Amer. J. trop. Med. Hyg., 22, 773-779.

Muller, R. L., and Taylor, M. G. (1972). On the use of the ZiehlNeelsen technique for specific identification of schistosome eggs. J. Helminth., 46, 139-142.

Nayar, A., Narayanan, J. S., and Job, C. K. (1972). The histopathological study of the early skin lesions in leprosy. Arch. Path., 94, 199-204.

Parelkar, S. N., and Stamm, W. P. (1973). Indirect immuno-fluorescent staining of trophozoites of Entamoeba histolytica. Trans. Roy. Soc. trop. Med. Hyg., 67, 659-662.

Parelkar, S. N., Stamm, W. P., and Hill, K. R. (1971). Indirect immunofluorescent staining of Entamoeba histolytica in tissues. Lancet, 1, 212-213.

Rees, R. J. W., and Ridley, D. S. (1973). Bacteriology and pathology of leprosy. In Recent Advances in Clinical Pathology, edited by S. C. Dyke, pp. 305-321. Churchill Livingstone, Edinburgh and London.

Ridley, D. S. (1973). The pathogenesis of the early skin lesion in leprosy. J. Path., 111, 191-206.

Rivera, E., Maldonado, N., Velez-Garcia, E., Grillo, A. J., and Malaret, G. (1970). Hyperinfection syndrome with Strongyloides stercoralis. Ann. intern. Med., 72, 199-204.

Robinson, G. L. (1968). The laboratory diagnosis of human parasitic amoebae. Trans, roy. Soc, trop. Med. Hyg., 62, 285-294.

Sargeaunt, P. (1962). Confirmation of amoebic cyst chromatoids by wet stain after Ridley's faecal concentration. Trans. roy. Soc. trop. Med. Hyg., 56, 12.

Scholten, T. (1972). An improved technique for the recovery of intestinal protozoa. J. Parasit., 58, 633-634.

Semple, A. B., Davies, J. B. M., Kershaw, W. E., and St. Hill, C. A. (1954). An outbreak of trichinosis in Liverpool in 1953. Brit. med. J., 1, 1002-1006.

Shute, P. G. (1966). The staining of malaria parasites. Trans. roy. Soc. trop. Med. Hyg., 60, 412-416. 
Shute, P. G., and Maryon, M. (1969). Imported malaria in the United Kingdom. Brit. med. J., 2, 781-785.

Symposium (1972). Serologic tests for malaria. Amer. J. trop. Med. Hyg., 21, 677-703.

Thompson, R. G. (1972). A simple concentration method for the detection of parasitic ova and cysts in faeces. J. clin. Path., 25, 546-547.

Thompson, R. G., Hutchinson, J. G. P., and Johnston, N. M. (1972). Survey of intestinal pathogens from immigrant children. Brit. med. J., 1, 591-594.

Thorpe, E., and Ford, E. J. H. (1969). Serum enzyme and hepatic changes in sheep infested with Fasciola hepatica. J. Path., 47, 619-629.

Turk, J. L., and Bryceson, A. D. M. (1971). Immunological phenomena in leprosy and related diseases. Advance Immunol., 13, 209-266.
Voller, A. (1971). The detection and measurement of malarial antibodies. Trans. Roy. Soc. trop. Med. Hyg., 65, 111-124.

Von Lichtenberg, F., Erickson, D. G., and Sadun, E. H. (1973). Comparative histopathology of schistosome granulomas in the hamster. Amer. J. Path., 72, 149-178.

Walshe, J. M. (1954). Echinococcosis alveolaris of the liver. J. Path. Bact., 67, 371-377.

Wiersema, J. P., and Binford, C. H. (1972). The identification of leprosy among 'epithelioid cell granulomas of the skin. Int. $J$. Leprosy, 40, 10-32.

Williams, H. H. (1965). Round worms in fishes and so-called 'herring worm disease'. Brit. med. J., 1, 964-967.

Woodruff, A. W. (1970). Toxocariasis. Brit. med. J., 3, 663-669.

Woodruff, A. W., Monath, T. P., Mahmoud, A. A. F., Pain, A. K. and Morris, C. A. (1973). Lassa fever in Britain: an imported case. Brit. med. J., 3, 616-617. 